\title{
ANALYSIS OF TWO HINGE INDETERMINATE ARCH USING COMPUTATIONAL TOOL
}

\author{
Ajay Rudakiya ${ }^{1}$, Maulik Sankhavara ${ }^{2}$, Payal Mehta $^{3}$ \\ ${ }^{I}$ Student, Institute of Technology, Nirma University \\ ${ }^{2}$ Student, Institute of Technology, Nirma University \\ ${ }^{3}$ Assistant Professor, Institute of Technology, Nirma University
}

\section{Synopsis}

Arch is a curved symmetrical structure spanning an opening which can be used as an alternative of beams because of their specific shape related advantages which turns to an economical structure for a larger span. Apart from said advantage it becomes essential for very long span structures like bridges.

The analysis method of the arch is based on its type and structural indeterminacy of the structure. The three hinge semicircular and parabolic arches can be solved using the standard practice of analysis. Due to redundancy of the two hinge arch a computational tool i.e. computer C language program is made for solving two hinge arch with 15 point loads.

This paper is an attempt to showcase the analysis criteria used in program for two hinged arch with point load which can be very useful in solving curved large span indeterminate structure.

Keywords: Two hinge arch, Indeterminate structures, C language program ***

\section{INTRODUCTION}

Arches is used in bridge construction and doorways. In past day, arch structure is constructed using stone and brick. In modern era, arch structure is constructed using reinforced concrete and steel. It is curved in shape. In this type of structure, horizontal forces at both supports are produce only under vertical load, which is called trust. As two hinge arch is statically indeterminate structure, it cannot be solved using equilibrium conditions. Castigliano's theorem of least work is the analytical method to find the redundant reaction at support for two hinged arch

\section{BEAM \& ARCH}

\begin{tabular}{|l|l|}
\hline BEAM & ARCHE \\
\hline $\begin{array}{l}\text { It transfers the load to end } \\
\text { support by bending \& shear } \\
\text { action. }\end{array}$ & $\begin{array}{l}\text { It transfers the load to end } \\
\text { support by axial } \\
\text { compression \& partly by } \\
\text { bending \&shear action }\end{array}$ \\
\hline $\begin{array}{l}\text { The material in most of the } \\
\text { portion is under stress } \\
\text { \&section is under-utilized. }\end{array}$ & $\begin{array}{l}\text { Due to equal distribution } \\
\text { of stress, the section is } \\
\text { fully utilized. }\end{array}$ \\
\hline $\begin{array}{l}\text { In beam, its bending } \\
\text { moment is high. }\end{array}$ & $\begin{array}{l}\text { In arches, its bending } \\
\text { moment is low compare to } \\
\text { beam. }\end{array}$ \\
\hline $\begin{array}{l}\text { Bending } \\
\text { Moment= } \mathrm{W}^{*} \mathrm{x}\end{array}$ & $\begin{array}{l}\text { Bending Moment=W } \\
\mathrm{H}^{*} \mathrm{y}-\end{array}$ \\
\hline
\end{tabular}

Bending moment is high so it leads to costly structure in terms of material requirement.

Bending moment is less compare to beam so it is economic structure in terms of material requirement.

\section{CLASSIFICATION OF ARCHES}

Based on shape

1. Steel arches

2. R.C.C arches

3. Masonry arches

Based on structural behavior

[1]. Two hinged arches

[2]. Fixed arches

[3]. Three hinged arches

\section{ANALYSIS OF TWO HINGED ARCHES}

A two hinged arch is statically indeterminate to single degree, since there are four reaction components to be determined while the number of equations available from static equilibrium is only three. Considering $\mathrm{H}$ to be the redundant reaction, it can be found out by only by the use of Castigliano's theorem of least work.

Thus, assuming the horizontal span remaining unchanged, we have,

$\frac{\partial U}{\partial H}=0$,

Where $\mathrm{U}$ is the total strain energy stored in the arch. Here also, the strain energy stored due to thrust and shear will be 
considered negligible in comparison to that due to bending.

$$
\begin{gathered}
\mathrm{U}=\int \frac{M^{2} d s}{2 E I} \\
\frac{\partial U}{\partial H}=\int \frac{2 M}{2 E I} \cdot \frac{\partial M}{\partial H} \cdot d s=\int \frac{M}{E I} \frac{\partial M}{\partial H} \cdot d s \\
\text { Now, } \mathrm{M}=\mu-\mathrm{Hy} ; \frac{\partial M}{\partial H}=-y \\
\frac{\partial U}{\partial H}=0=\int \frac{(\mu-H y)(-y)}{E I} d s \\
\mathrm{H} \int \frac{y^{2} d s}{E I}=\int \frac{\mu y d s}{E I} \\
\mathrm{H}=\frac{\int \frac{\mu y d s}{E I}}{\int \frac{y^{2} d s}{E I}}
\end{gathered}
$$

Taking $\mathrm{dx}=\mathrm{ds} \cos \theta \quad$ so, $\mathrm{ds}=\mathrm{dx} \sec \theta$

From that we get,

$$
\mathrm{H}=\frac{\int \mu \cdot y d x}{\int y^{2} d x}
$$

\section{NUMERICAL}

A parabolic Arch hinged at the ends has a span $30 \mathrm{~m}$ and rise $5 \mathrm{~m}$. A concentrated load of $12 \mathrm{kN}$ acts at $10 \mathrm{~m}$ from the left hinge. The second moment of area varies as the secant of the slope of the rib axis. Calculate the horizontal thrust and the reactions at the hinges. Also calculate the maximum bending moment anywhere on the arch.

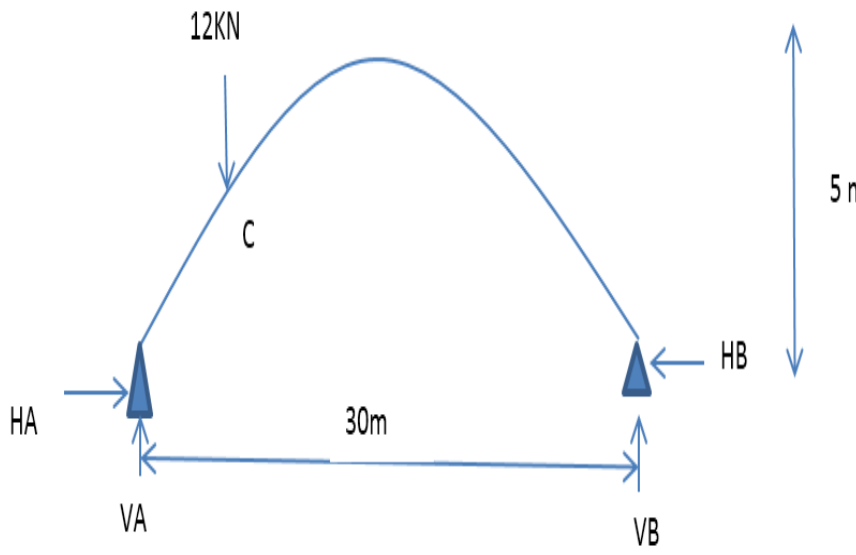

$\Sigma \mathrm{M} @ \mathrm{~A}=0$

$\mathrm{V}_{\mathrm{b}} * 30=12 * 10$

$\mathrm{V}_{\mathrm{b}}=4 \mathrm{KN}$

Now, $\mathrm{V}_{\mathrm{a}}+\mathrm{V}_{\mathrm{b}}=12 \mathrm{kN}$

So $\mathrm{V}_{\mathrm{a}}=8 \mathrm{kN}$

Equation of parabola,

$\mathrm{Y}=\frac{4 h x(L-x)}{L^{2}}$

$\mathrm{Y}=\frac{4 * 5 * x(30-x)}{30^{2}}$

$\mathrm{Y}=\frac{x(30-x)}{45}$

Now, horizontal thrust can be found out from the equation

$$
\mathrm{H}=\frac{\int \mu \cdot y d x}{\int y^{2} d x}
$$

$\mu=8 \mathrm{x}$, for $\mathrm{AC}$ portion

$\mu=8 \mathrm{x}-12(\mathrm{x}-10)$, for $\mathrm{CB}$ portion

$\mu=(120-4 x)$

$$
\begin{aligned}
\int_{0}^{30} \mu y d x & =\int_{0}^{10} 8 x y d x+\int_{10}^{30}(120-4 x) y d x \\
= & \int_{0}^{10} \frac{8 x^{2}(30-x)}{45}+\int_{10}^{30} \frac{4 x(30-x)^{2}}{45} \\
\int_{0}^{30} \mu y d x & =\frac{44000}{90} \\
\int_{0}^{30} y^{2} d x & =\int_{0}^{30} \frac{x^{2}(30-x)^{2} d x}{45^{2}} \\
& =\frac{1}{45^{2}} \int_{0}^{30}\left(900 x^{2}+x^{4}-60 x^{2} x\right) d x \\
\int_{0}^{30} y^{2} d x & =400 \\
\text { So, } \mathrm{H} & =\frac{44000}{9 * 400} \\
\mathrm{H} & =12.22 \mathrm{kN}
\end{aligned}
$$

Now, Resultant reaction $\mathrm{R}_{\mathrm{a}}=\sqrt{8^{2}+12.22^{2}}=14.61 \mathrm{kN}$

$$
\begin{aligned}
& \tan \theta a=\frac{8}{12.22}=0.655 \\
& \theta_{\mathrm{a}}=33.21^{\circ} \\
& \mathrm{R}_{\mathrm{b}}=\sqrt{4^{2}+12.22^{2}}=12.85 \mathrm{kN} \\
& \theta_{\mathrm{b}}=\tan ^{-1} \frac{4}{12.22}
\end{aligned}
$$

Maximum BM will occur in AC, just below the load Rise of arch at that point

$$
\begin{gathered}
\mathrm{Y}=\frac{x(30-x)}{45}=\frac{10(30-10)}{45}=40 / 9 \mathrm{~m} \\
\mathrm{M}_{\max }=8 * 10-12.22 * 40 / 9=25.49 \mathrm{kNm}
\end{gathered}
$$

\section{SUMMARY}

Thrust of the arch is inversely proportional to the rise of the arch.In order to calculate the bending moment in any cross section of the arch, the bending moment at the same section of the reference beam should be decreased by the value $\mathrm{H}^{*} \mathrm{yk}$. Therefore, the bending moment in the arch less than that of in the reference beam. This is the reason why the arch is more economical than simply supported beam, especially for large-span structures. Two hinged arch is an indeterminate structure, so C-program is made to solve this type of structure. Support reactions can be determined by using this computational tool.

\section{REFERENCES}

[1]. Hibbeler R. C., "Structural Analysis", Pearson, sixth edition

[2]. Walter J. Austin, Timothy J. Ross, "Elastic Buckling of Arches under SymmetricalLoading",Journal of the Structural Division, Vol. 102, No. 5, May 1976, pp. 1085-1095

[3]. Devdas Menon, "Structural Analysis", Narosa Publishing House 


\section{APPENDIX FLOWCHART}

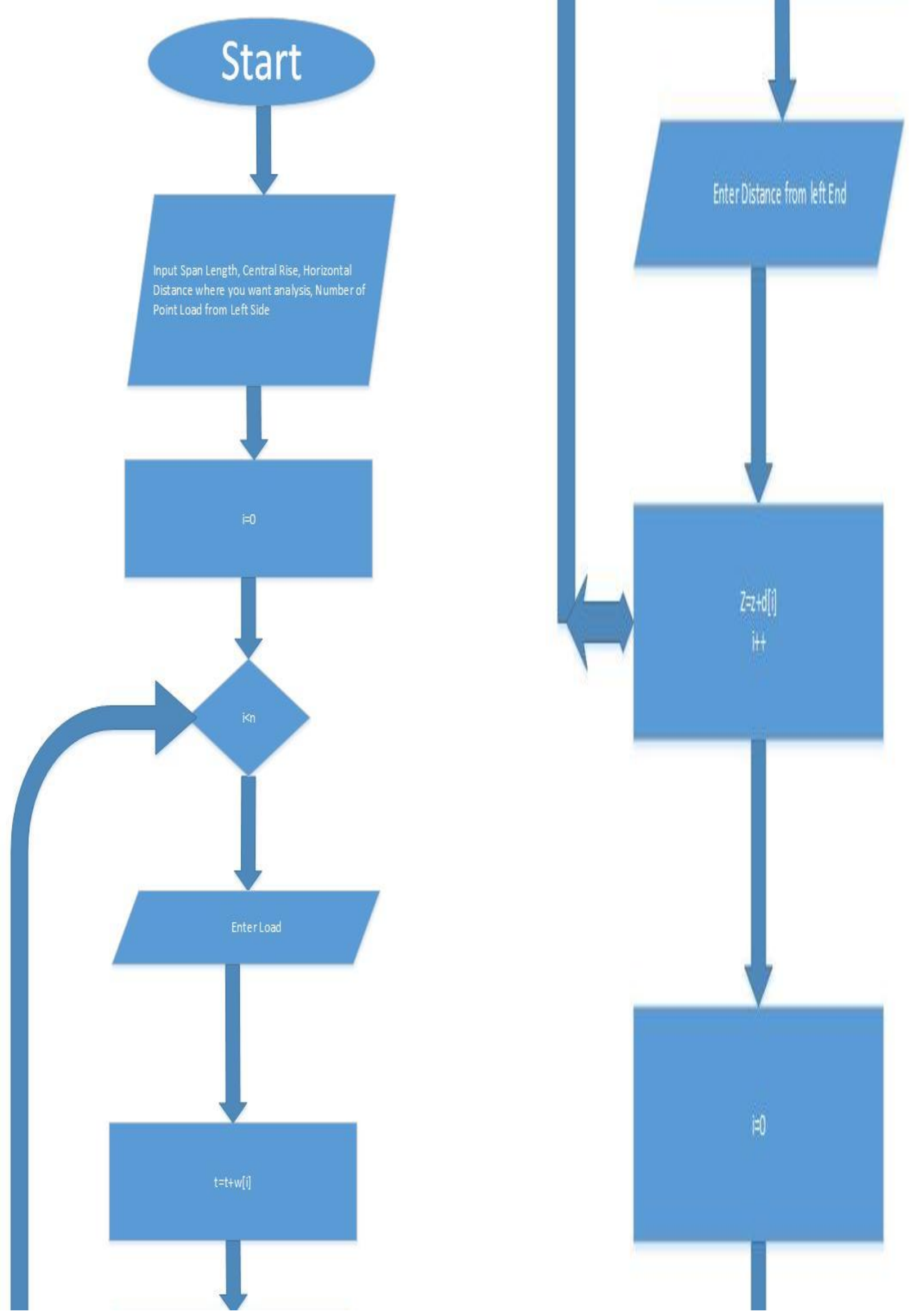



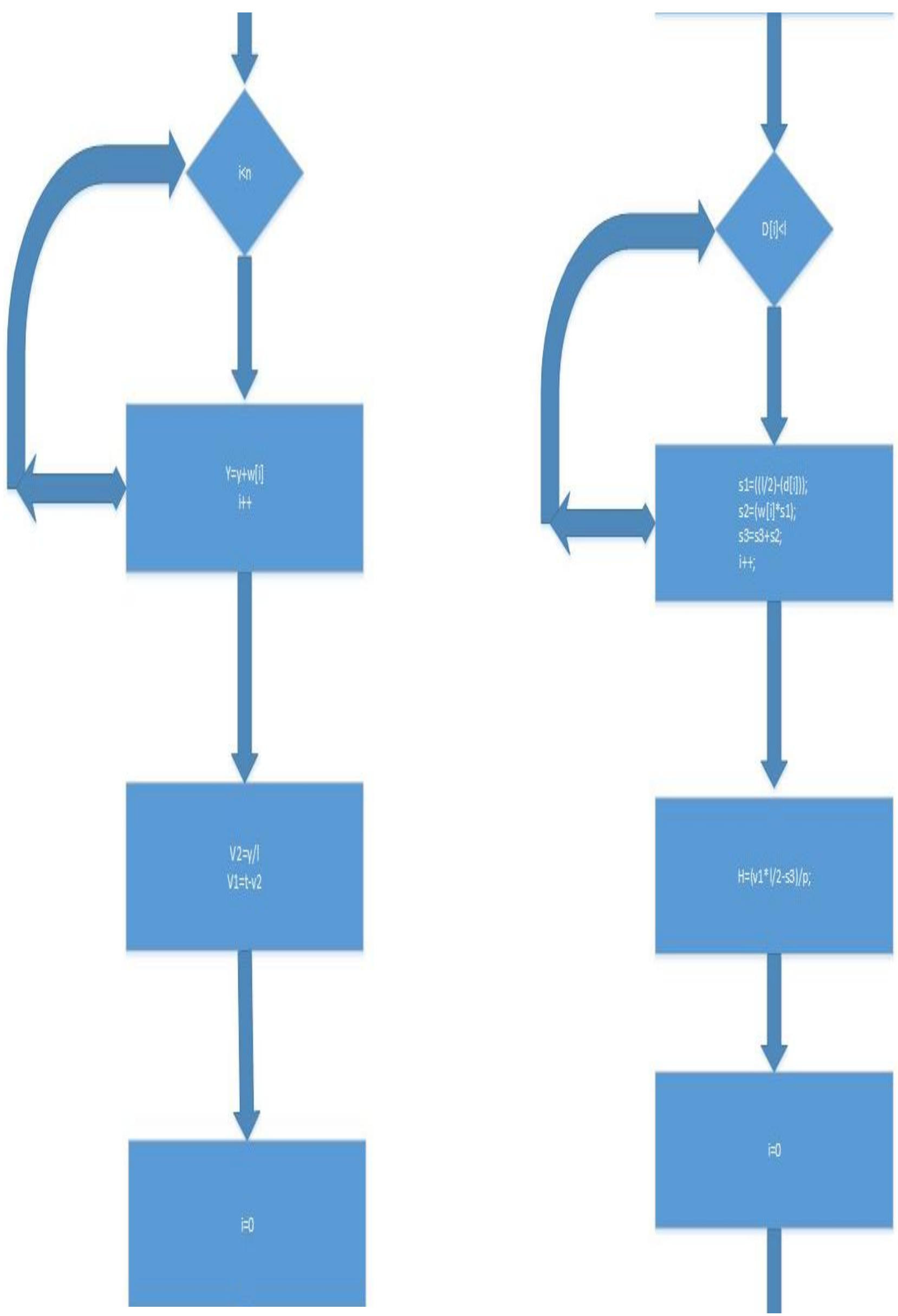


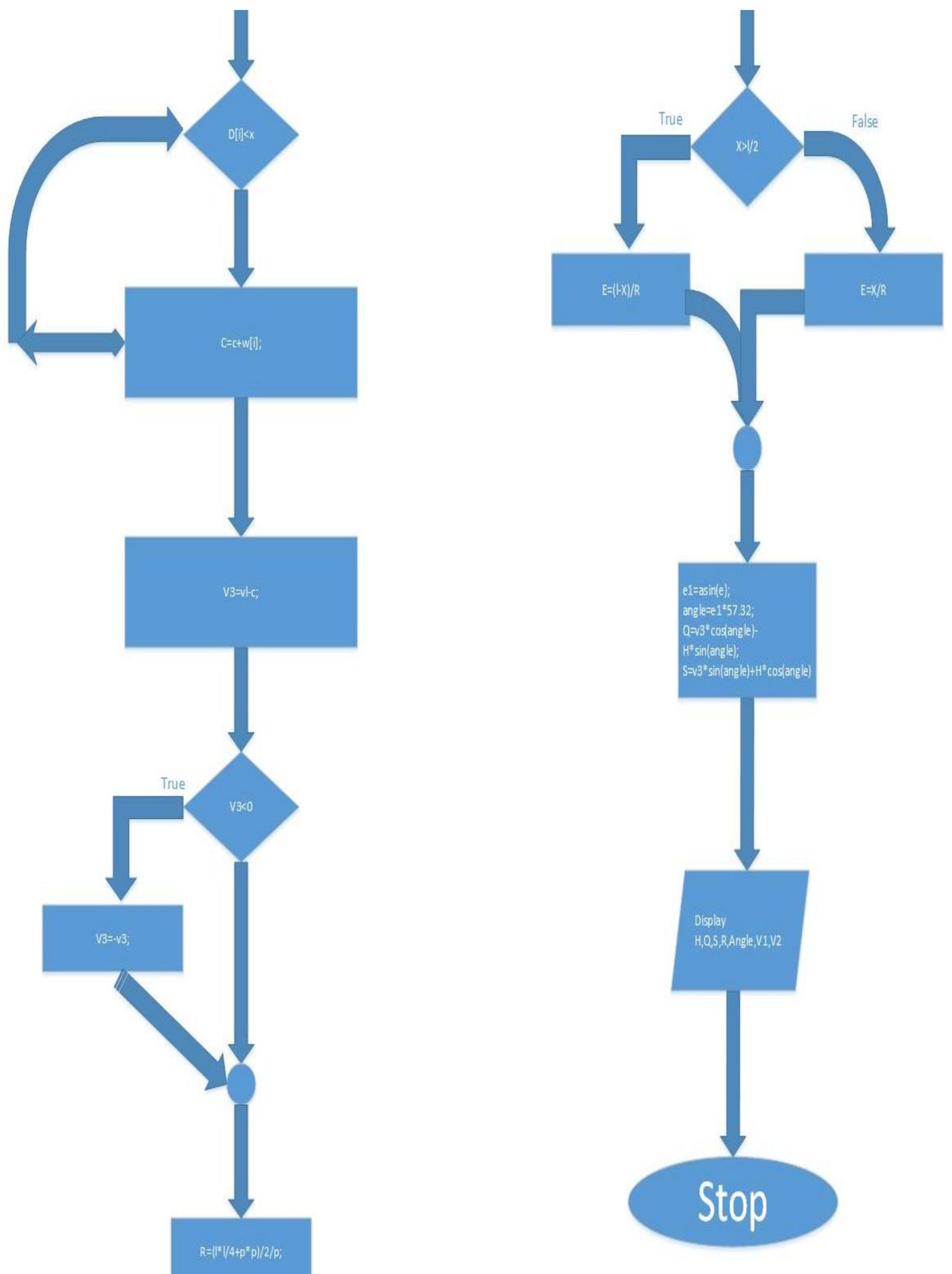

